\title{
Emphasizing Student Emotional Education Optimizing Chinese Teaching in Junior Middle School
}

\author{
Rong Lin \\ China West Normal University Institute of Teacher Education; Sichuan, Nanchong; 637000, China.
}

Keywords: emotional education; Chinese of junior middle school; teaching efficiency.

\begin{abstract}
The self-consciousness of junior middle school students has been gradually strengthened, and their emotional experience has been gradually enriched. Teachers can use language education to achieve better teaching results when developing Chinese language teaching. This article first states the related concepts of emotional education, so that everyone has a specific understanding of it, then research the application value of emotional education in Chinese teaching, and make the relevant educators clarify the necessity of the application of emotional education, then analyze the current teaching situation, Based on the current situation, this paper discusses the path of emotional education reinforcement in Chinese teaching of junior middle school, and hopes to further promote the development of education in China.
\end{abstract}

\section{Introduction}

With the development of national education, quality education has become a new direction for education development. The teaching of Chinese in junior high schools plays an extremely important role in cultivating the overall quality of students. The proposal of emotional education,

It indicates the path to strengthen the teaching of Chinese teaching in junior middle school, in order to have a clearer understanding of it, this study is carried out.

\section{An Overview of Emotional Education.}

Emotional education means that in carrying out education and teaching activities, it is necessary to use the relevant knowledge of psychology,Learning goal oriented, through to carry out related activities, to strengthen students' emotional experience, including learning ideas, emotions and learning attitude, etc., and then deliver improved the teaching effect, to ensure the smooth completion of the teaching goal [1].In the emotional education implemented in Chinese teaching of junior high school, specifically refers to the implementation of Chinese teaching activities, the text of the text reflects the emotional use of reasonable means of teaching to students, and further strengthen the teaching content, teaching subjects and teaching methods of the balance Sex, improve the quality of teaching.The emotional and reasonable teaching methods of the text are conveyed to students, which further strengthens the balance between teaching contents, teaching subjects and teaching methods, and improves the teaching quality.For Chinese subject teaching activities, to the effect of emotional effective feature in the teaching activities, realize the students' emotional resonance, so that the students can better in-depth teaching text, and then promote the enthusiasm of students to participate in teaching activities effectively, promote the development of quality education.

\section{The Application Value of Emotion Education in Chinese Teaching of Junior Middle School}

The new curriculum standard further determines the application value of emotional educationin Chinese teaching of junior middle school, It requires students to take students as the subject of the classroom in their education activities, and at the same time, they must also reflect the humanistic characteristics in the development of Chinese language teaching. In carrying out education work for students of junior high school, it is necessary to effectively integrate emotional education in language teaching and further improve the overall quality of students [2]. As the students entered junior high 
school, both physical and psychological changes took place to a certain extent. Emotional education can be applied to students in a rational manner so that teaching behaviors can better meet student needs. At the same time, Chinese language teaching materials can be effectively combined. Digging can stimulate the inner feelings of the students and thus cultivate sentiment, greatly improving the comprehensiveness of students' development. In the development of Chinese language teaching, because of its itself has the characteristics of instrumental and humanism exist at the same time, for students correct speech expression, has extremely important practical significance, and also essential for the promotion of students' comprehensive quality. And the effective application of emotion education further promoted the development of Chinese education.

\section{Current Teaching Situation}

\subsection{Heavy Atmosphere in the Classroom.}

In the process of educational development, the history of Chinese subjects is relatively long-term. But with the development of the modernization, the demand of the students to participate in the Chinese teaching also presents a trend of diversification, but there's a part of teachers in education behavior, still use the traditional model [3].Adopting the traditional duck-feeding teaching method,and did not further recognize students' dominant position in participating in teaching activities, there is no exploration of students' learning interest in the conduct of teaching activities, which greatly limits the enthusiasm of students to participate in the study, which is not conducive to the further development of education teaching.

\subsection{Insufficient Emotional Experience.}

The survey found that most students did not have a deep understanding of education when participating in Chinese classroom, and the main reason was the lack of teachers' ability [4].In the process of emotional education, the teacher should guide the students to read the text, determine the emotional tone of the text, and then make the students more familiar with the content of the textbook so that they can participate in the classroom better.However, in the current teaching work, most teachers directly leave this part of the content to the students. Due to the lack of students, life experience, it is difficult for students alone to fully understand the content of the text so that some students become inert and cannot read the content of the text.

In-depth explorations do not have a basic understanding of the center of the article, which in turn deviates its emotional experience, it has a bad influence on its participation in learning, which is not conducive to the further development of education.

\subsection{Backward Management Concept.}

In the current education construction, the majority of schools will increase the enrollment rate as the teaching focus. The specific performance of Chinese teaching is that emotional education does not improve students' language performance, and there is no further application value in the promotion of graduation rate [5].Based on this, in the educational activities, teachers do not place the classroom focus on the analysis of texts of textbooks. They can not effectively guide students to excavate the author's writing ideas and master emotional expression, but place the focus of the classroom on the examination skills. Under the long-term influence of education, it is very difficult for students to explore the article, which is not good for the center of the article, which is not conducive to the cultivation of students' language thinking.

\section{The Path of Emotional Education Reinforcement in Chinese Teaching of Junior Middle School.}

\subsection{Intensive Classroom Introduction.}

In the course of carrying out Chinese teaching, classroom introduction is an important guarantee to ensure the effect of classroom teaching. It is also of great practical significance for students to participate in the classroom and to melt into the emotional atmosphere of texts. However, some teachers are not able to guide students correctly when they are working on education [6]. At the same 
time, the study of Chinese subjects has a high degree of subjectivity. If students can't guide students correctly, students will think that the classroom is boring,and resulting in a tired school psychology and unfavorable to the development of the education industry.Based on this, in the process of Chinese teaching work, teachers need to be reasonable emotional factors into classroom import link, this can make students better to dissolve into the classroom, and further enhance the enthusiasm of students to participate in the study.For example, in the education of the "snow to the tune of Chin Yuan Chun" lesson,teachers can ask students to imagine ice and snow world in winter, and introducing students into the situation, then teaching, this can make students better enter the classroom situation, thus having deeper feelings for the article and improving the classroom effect.

\subsection{Use Multimedia Wisely.}

In literary works, there are many concrete images in life. When teachers design teaching content, they can effectively apply multimedia technology, this can breaking the limitations of the traditional teaching way,and more specific image lecture this knowledge, to realize the richness of teaching content, so that students can better enter the learning scene, integrated into the text range [7].Teaching in a specific situation can give students a more specific understanding of the context, thus realizing the innovation of learning mode to further satisfy their individual needs.For example, in the teaching of the " Kong Yiji " lesson, teachers can use multimedia to play "Kong Yiji" movie clips, so that the students have a clear understanding of the situation of the article, and thus enable students to better integrate in the textbook.At the same time, the teacher can also by playing lu xun's life environment, causes the student to the text of the underlying thought in-depth exploration, and more in-depth understanding of the article content, for experience master of emotion and the author want to convey thoughts, improve the students' literacy.

\subsection{Improve the Quality of Teachers.}

It is necessary to apply emotional education in Chinese language class, which requires a higher professional quality. Teachers need to carry out some auxiliary work before the class is carried out.Before carrying out the work, the teacher must fully understand the students' learning status, and clarify the students' individual needs, and then conduct the teaching based on the students' personalized needs,only in this way can improve the relevance of education. At the same time, teachers need to deeply analyze the text teaching, clarify the text center idea, and excavate the content that the author wants to express more deeply, laying the foundation for the effective development of the classroom.Before the class starts, it is necessary to prepare effective teaching work and realize efficient classroom.For example, in the course of teaching "the view of the sea", teachers need to use their professional qualities to tell students about the life of cao cao as well as the overall environment of The Three Kingdoms period,This will enable students to have a deeper understanding of the context, and strengthen students, understanding of the text, to ensure the efficiency in the course.

\subsection{Set the Suspense.}

Usually, there is a certain suspense setting in literary works, which can greatly enhance the readers' interest in reading. By setting suspense in Chinese teaching, students' curiosity can be effectively utilized to make it more enthusiastic to study, so that they can participate in the classroom better and ensure the classroom effect. When teaching "Fan Jin was raised" lesson,

Teachers can ask a question before the class starts: Everybody guesses what happened after Fan Jin was raised, then let everyone discuss freely and analyze what might happen after Fan Jin was raised. let the students read the article and make clear what happened after FAN Jin was raised. After reading the article, students will have some doubts about after going crazy. At this time, the teacher can throw a question again: Why does Fan Jin appear after he was raised? Then ask the students to look up the information on their own and ask for answers to the questions. Teaching through the above methods can better meet the people-oriented concept of modern education and cultivate students' exploration spirit, and further enhance the effectiveness of the classroom.

\subsection{Improved Language Application.}

In order to enable students to better understand the teaching materials when carrying out Chinese language classroom teaching activities in junior high schools, in order to make students better understand the teaching material, teachers can effectively combine the teaching material content and 
students' personality characteristics, reasonable use of language for students to create a teaching situation, so that the students can be more reasonable to understand the article, which make it get edify sentiment, causes the student to resonate with text, so as to better participate in classroom [8].At the same time, by reasonable application of language arts teachers, can also be teaching contents and students' real life together effectively, make students better accept articles in emotion, and further improve themselves life concept.For example, in the "Spring" lesson, teachers can guide students into the spring situation using meditation: we walk on the grass that has just sprouted green, and there are several small flowers in the middle. Birds Also began to return from the south, occasionally hear a few birds singing, you hear, the spring is thaw. Using language awareness to make students deeper into the context of the lesson, and on the basis of this, to develop a classroom, students can better appreciate the beauty of spring and have a more accurate understanding of the emotions the author wants to express, so as to enhance students' literacy.

\section{Conclusion}

In the development of education, emotion education has extremely important practical significance, which has an indispensable application value for junior middle school Chinese teaching.In the research of this paper, it is found that due to the influence of exam-oriented education, there are certain deficiencies in the current Chinese language teaching on the junior high school campus, which is not conducive to the development of students' quality.In carrying out Chinese language teaching, through intensifying the introduction of classrooms, making rational use of multimedia, and improving the quality of teachers, Setting reasonable suspense and improving language application in the classroom can better realize emotional education, further improve the teaching effect, and promote the development of education in China.

\section{References}

[1]. Li Cunan. How to Inspire Students' Emotions in Chinese Teaching of Junior Middle School [J]. China Youth, 2017(30): 182-183.

[2]. Wang Tong. Emphasizing Subject Emotional Infiltration and Enriching Students' Humanistic Feelings - - Analysis of the Emotional Education Strategy in Chinese Teaching of Junior Middle School [J]. China Teachers, 2016(1):44-44.

[3]. Zhao Li. The Application of Emotional Education in Junior High School Teaching in New Curriculum Reform[J]. Proceedings of the 100th Magazine, 2016(5):43-43.

[4]. Yu Meng. My opinion on the importance of emotional education in Chinese teaching of junior high school [J]. Emotional Reader, 2016(17):10-10.

[5]. Guo Changbao. How to give students the best emotional education in Chinese teaching of junior high school[J]. Educational Modernization, 2016(22):127-129.

[6]. Zhao Meili. The Application of Emotional Education in Chinese teaching of junior high school[J]. Care for Tomorrow, 2016(5):55-55.

[7]. Li Haiyan. Application of Emotional Teaching in Chinese teaching of junior high school[J]. Extracurricular Chinese, 2016(14):136-136.

[8]. Liu huan, zhai zhaotao. Analysis of the application of emotion education in Chinese teaching of junior high school[J]. Chinese education technology equipment. 2016(7):95-96. 